\title{
RESERVES FOR ENERGY EFFICIENCY IN PROCESSING AND STORAGE OF FRUIT AND VEGETABLE PRODUCTS IN THE REPUBLIC OF UZBEKISTAN
}

\section{RADJABOV. A, ESHPULATOV. N \& NABIEV. S}

Tashkent Institute of Irrigation and Agricultural Mechanization Engineers, Tashkent, Uzbekistan

The article analyzes the existing technology of processing and storage of fruit and vegetable products in terms of their energy intensity. The paper uses a new approach to the evaluation of energy efficiency of processing and storage of food products, developed by the authors, taking into account not only the energy costs but also the energy content (energy content) of the final product. To improve the energy efficiency of the drying process, on the duration of which its energy intensity and energy content of dried products depend, an electro-impulse treatment of the material before drying is proposed, which ensures the maximum necrosis of tissue cells, as the main factor preventing moisture removal. This electro-technological method is also recommended for the processing of fruits and vegetables and grapes before squeezing out the juice. Recommendations are given for increasing the efficiency of storing vegetables and fruits with the use of electro-impulse and electron-ion technology, which ensures the safety of products up to $86 \%$. The use of renewable energy sources, in order to increase the energy efficiency of processing and storage of fruit and vegetable products and grapes, is indicated in the work in a promising direction.
\end{abstract}

KEYWORDS: Energy Efficiency, Energy Value, Energy Resources, Ionization Blanching, Dried Products, Zone Drier \& Renewable Energy Sources (RES)

Received: Sep 15, 2018; Accepted: Oct 05, 2018; Published: Nov 15, 2018; Paper Id: IJEEERDEC20181

\section{INTRODUCTION}

In the conditions of a market economy, the efficiency of the production of end products of crop production largely depends on the expenditure of energy resources and, to a lesser extent, on the energy value of the food products themselves. In this regard, one of the main requirements for the technology of processing and storing fruits and vegetables and grapes is to ensure the maximum conservation of energy value and vitamin content, with minimal energy expenditure. The thermal processes of processing and storing fruits and vegetables and grapes are very energy intensive. Existing technologies for the production of dried products and the production of fruit and vegetable juice include a variety of technological processes, among which heat processes consume more than 92 percent of the total energy expended on all processes (Figures. 1 and 2). 


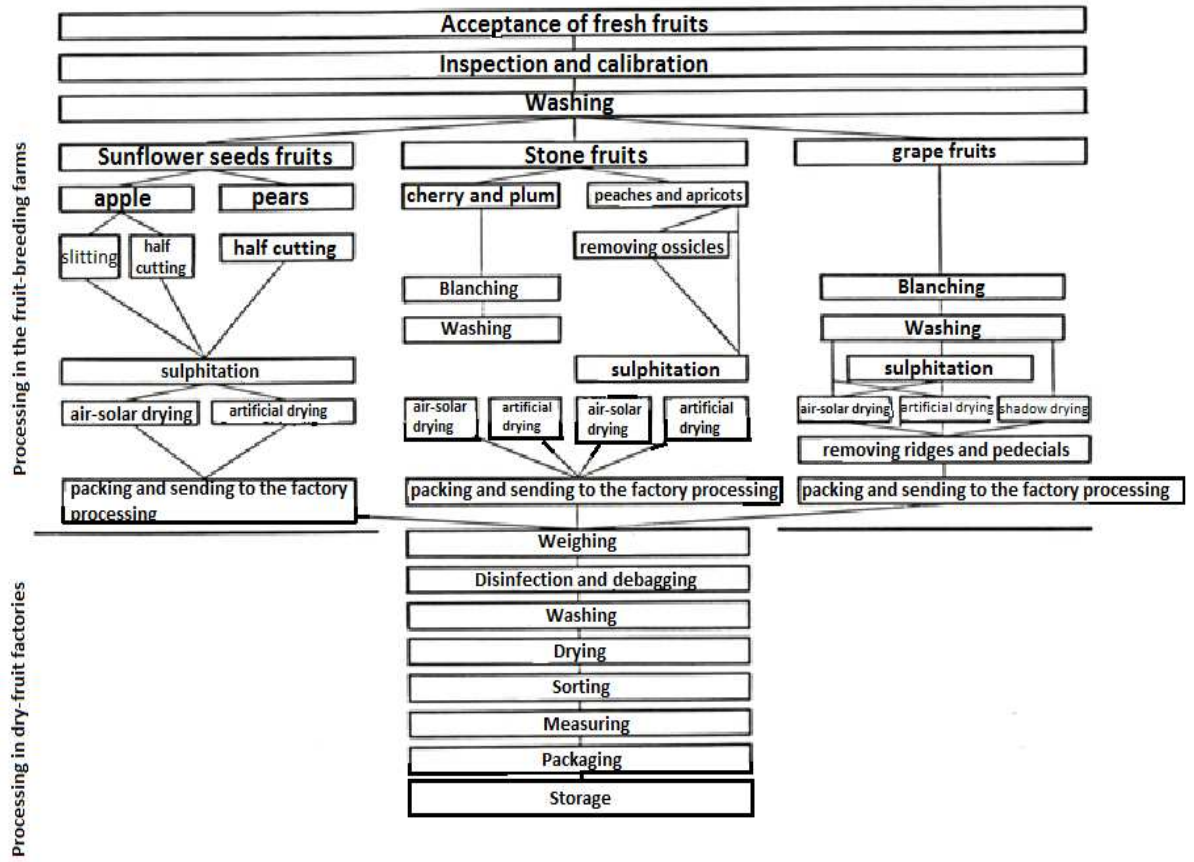

Figure 1: Diagram of the Existing Technology of
Production of Dried Fruits and Sultana Grape

Existing developments to improve the energy efficiency of fruit and vegetable processing and grapes mainly involve the technical improvement of the device and the optimization of the regimes and process parameters / 1,2,3,4,5/. The technology of drying fruits and grapes by means of preliminary mechanical (cutting into segments) and thermal (blanching) processing with a slight acceleration of the process (by 10,.., 15\% in the initial drying period), because of the high energy consumption of the balancing process and loss of nutrients in practice it is not widely used $(6,7,8)$.

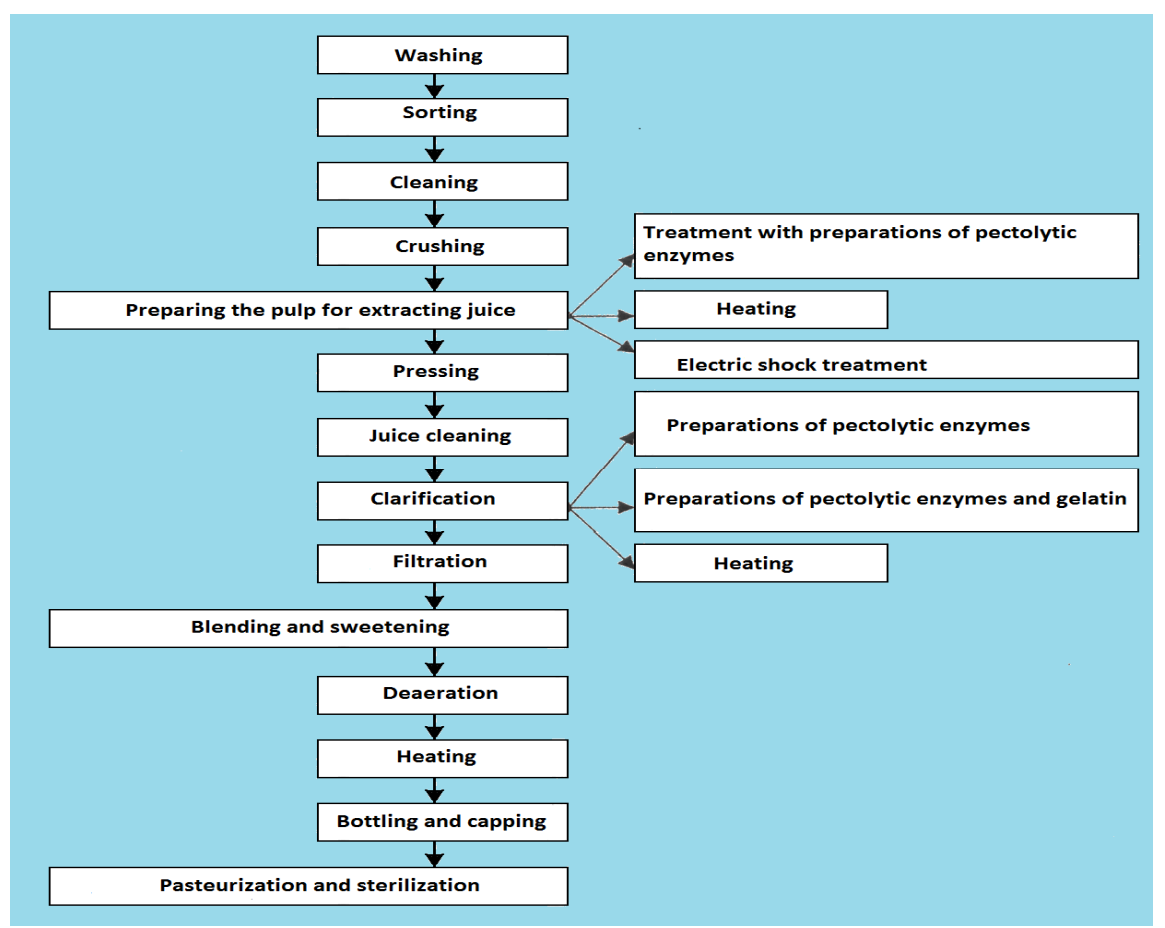

Figure 2: Diagram of the Existing Technology of Juice Production 
Currently, in the production of dried fruits and sultana grape, sun-air drying is mainly used, which lasts for a long time (25-30 days) outdoors in unsanitary conditions. It is of interest to develop researchers dedicated to the intensification of dehydration of plant materials due to the necrosis of tissue cells by heating them with an electric current to the temperature of thermo plasmolysis $(9,10,11)$. Due to the lack of energy-efficient technological and technical solutions for processing and storage of fruit and vegetable products, about 30\% of fresh produce in Uzbekistan currently does not reach consumers.

\section{MATERIALS AND METHODS}

\section{Methods of Research}

When assessing energy efficiency, the actual technologies for processing and storing fruit and vegetables were used by the method of analysis, analytical descriptions of the law of conservation of energy and the energy characteristics of technological installations. In studies on the development of an effective electro physical method for pretreatment of fruit-bearing products and the establishment of their parameters, the laws of biophysics, electrical engineering, and laws transfer and absorb energy by matter. When developing the drying technology, the laws of thermodynamics, the equations of thermal and material balance, were used.

\section{RESULTS}

The experience of the world and domestic practice shows that in the processes of heat treatment of plant materials, the loss of nutritional value of processed products is directly proportional to the duration of the process. In the process of drying fruits and vegetables, the living cells of their tissue, as a material of biological origin, have great obstacles to the removal of moisture, which leads to an increase in the duration of the process, which in turn leads to a significant decrease in the energy value and content of vitamins in the finished product. Long-term research conducted by us, in response to the existing problem, showed that in order to reduce the energy intensity of the drying process and extract juices from fruit and vegetable products, it is necessary to neutralize the main obstacle to the movement of moisture and juice from plant materials. The death of tissue cells due to the use of the destructive effects of electro-physical factors. Of the many electro physical factors that exert a destructive effect on the cells of tissues of plant origin, taking into account the peculiarities of technological and technical realization of the processing process, we established that the most effective is the electro pulse action/ $12,13,14,15,16$ /. To implement the decision and verify it in real conditions, we developed a pilot-industrial sample of an apparatus for the electrical impulse processing of fruits and vegetables and grapes before drying and extracting the juice, the general form of which is shown in Figure 3

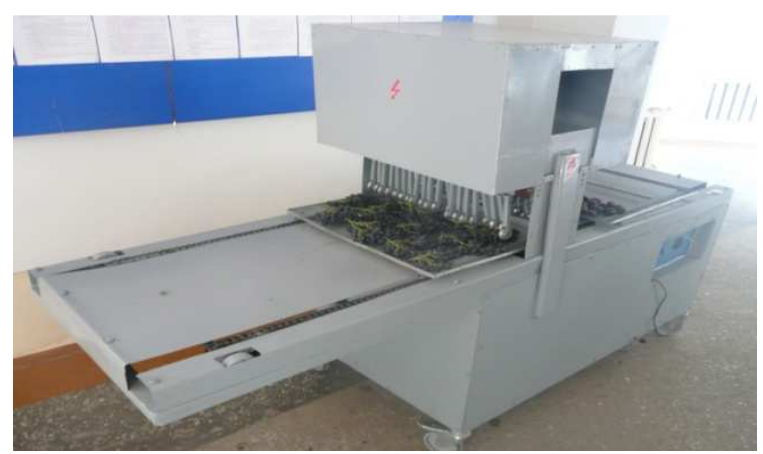

Figure 3: Experimental and Industrial Sample of an Installation for Electro Impulse Processing of Fruit and Vegetable Products and Grapes 
The investigation of the drying process of fruit and grapes showed that the most effective method of inputting energy (radiation, convective, conductive electromagnetic, etc.), dried material, is a convective method with stepped changes in the temperature of the coolant / 17, $18 /$.

To check the adopted drying technology, we developed a laboratory model of a 4-zone drying plant equipped with a solar air heater, a heat exchanger for recycling heat, leaving the spent coolant, from the 4th zone and using the selected heat from the mass carried away by dried products from the 5th zone (Figure 4).

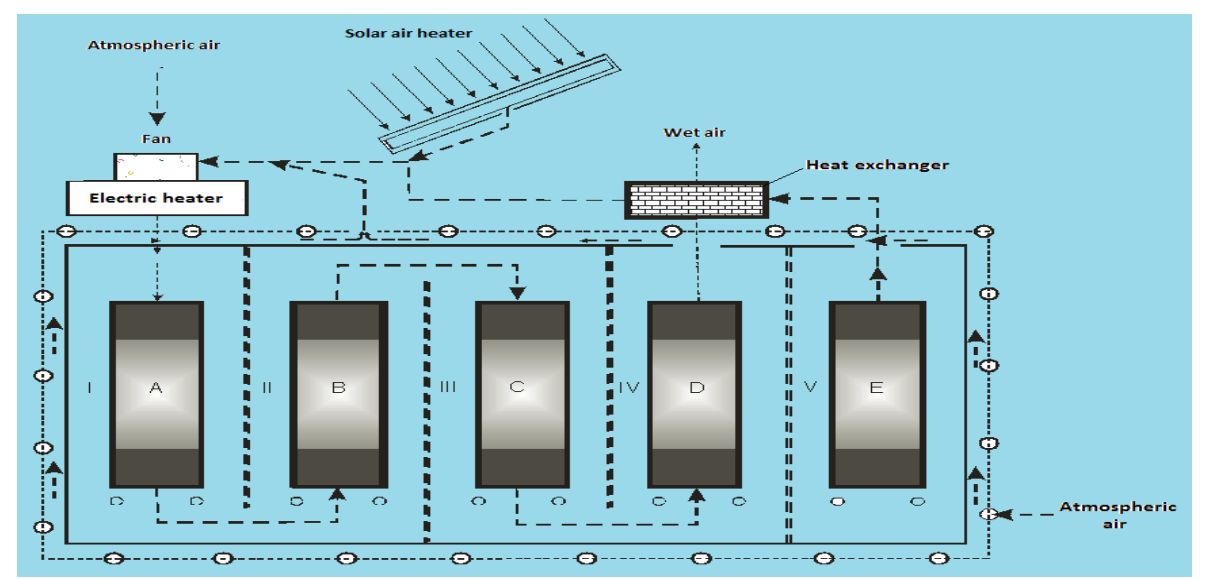
A, B, C, D, E - Trolleys with Dried Products
I-IV Section of the Drying Chamber;
V - Cooling Chamber

Figure 4: Diagram of the Laboratory Model of the Zone Convection Drying Plant with the Indication of the Movement of the Drying Agent and the Drying Products

Figures 5 and 6 show a new technology and equipment for the production line for dried fruits and sultana grape where the first-stage pre-drying blanching process has been replaced by electric pulse treatment and a power-hungry drying unit is offered a zone dryer with a soldering heater, a heat-exchanger, and a heat exchanger. Research carried out to improve the technology and technology of juices production from fruit and vegetable products and grapes showed that electric pulse technology pre-treatment increases the efficiency of juice production.

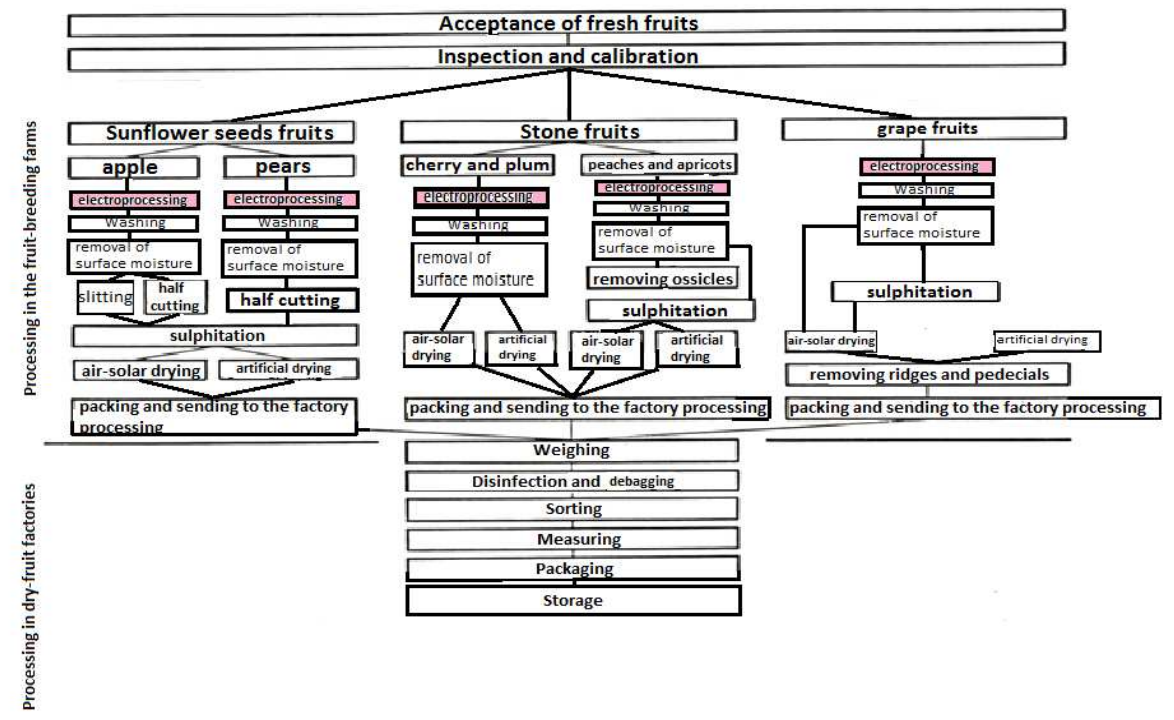

Figure 5: Scheme of the Proposed Technology for the Production of Dried Fruits and Sultana Grape 

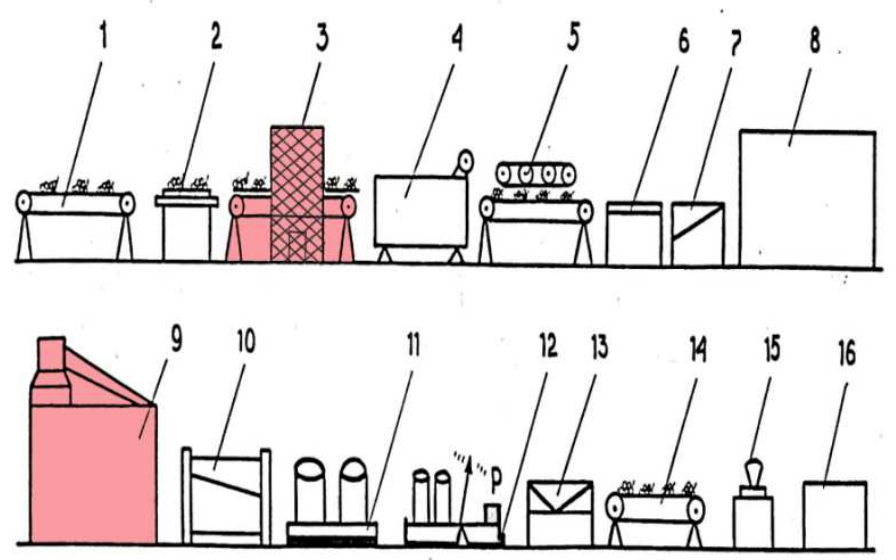

1 - Inspection conveyor; 2 - Tray; 3 - Installation for electrical processing;

4 - Washer, 5 - Conveyor with a moisture removal device;

6, 7-Machine for cutting and removing pits; 8 - Device for fumigation;

9 - Electric heat convection zone dryer;

10 - Special machine for cleared from branches and pedicels;

11 - In tare for sending to the factory processing; 12 - Weighing on scales;

13 - Pest control; a 14 - Sorting conveyor; 15 - Dosage on scales;

16 - Packing machine.

Figure 6: Scheme of the Location of Technological Equipment of a New line for Production of Dried Fruits and Sultana GRAPE

Research carried out to improve the technology and technology of producing juices from fruit and vegetable products and grapes showed that electro-impulse treatment increases the efficiency of juice production and positively affects the amount of juice yield by a natural leakage prior to the pressing process. The power of the electric drive of the press installation is reduced because for squeezing the juice from the tissue with the dead cells, less pressure is required compared to the tissue in living cells $(19,20)$. Figure 7 shows the scheme of the proposed technology of juice production using the technology of preliminary electro pulse treatment.

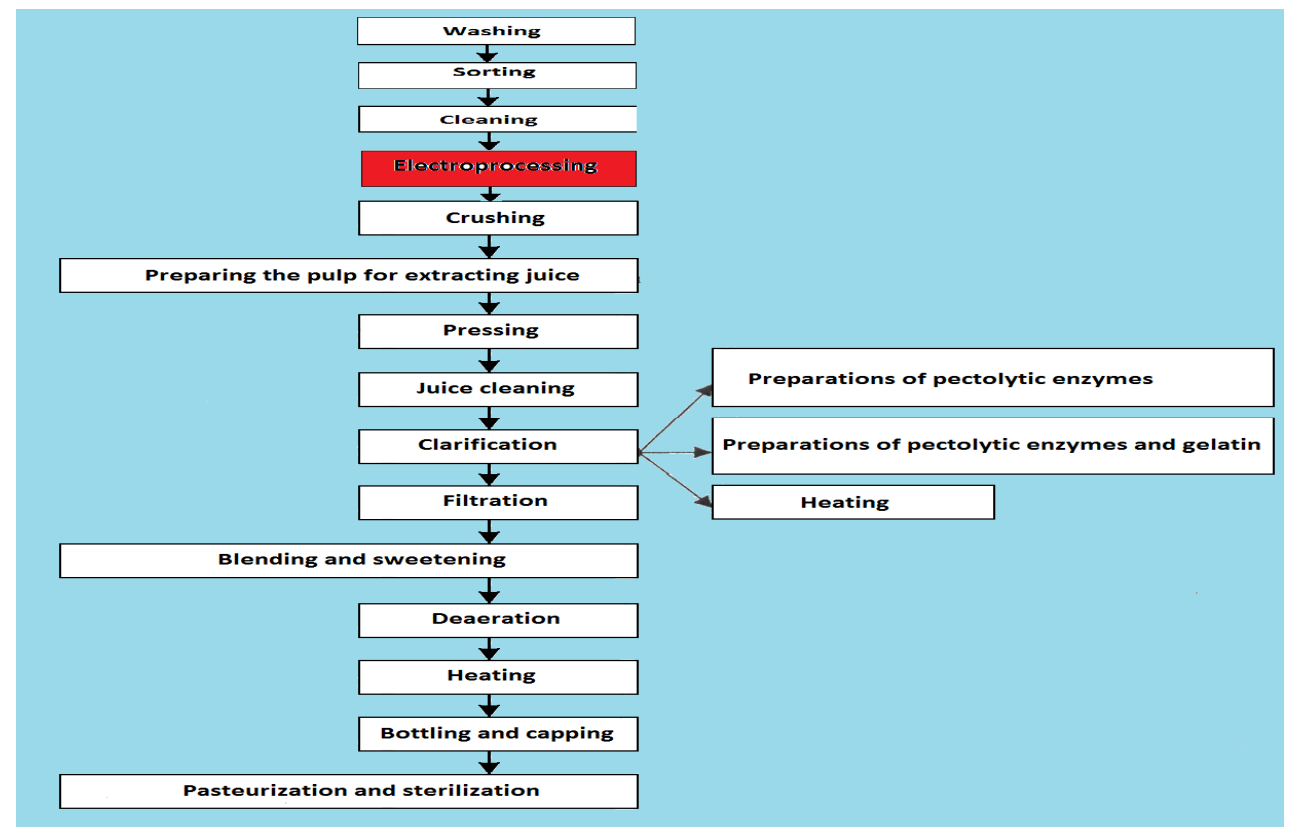

Figure 7: Scheme of the Proposed Technology of Juice Production with Electro Pulse Treatment 
Checking the installation in production conditions, showed that the preliminary electro pulse treatment accelerates the drying process 1.5-1.8 times and reduces the loss of nutrients by 5-7\% and the juice yield increases by $10-15 \%$. Also, a positive effect of electro-impulse treatment of fruits and grapes was revealed before squeezing juice for the duration of juice storage.

Comparative indicators of the effectiveness of methods for processing fruits of vegetable products before drying and squeezing of juice are shown in Figure 8.

There are many technologies for storing fruit and vegetable products, among which the greatest interest is storage in a vacuum and in the ozone medium, which ensures a reduction in product losses due to a decrease in the respiration of tissue cells.

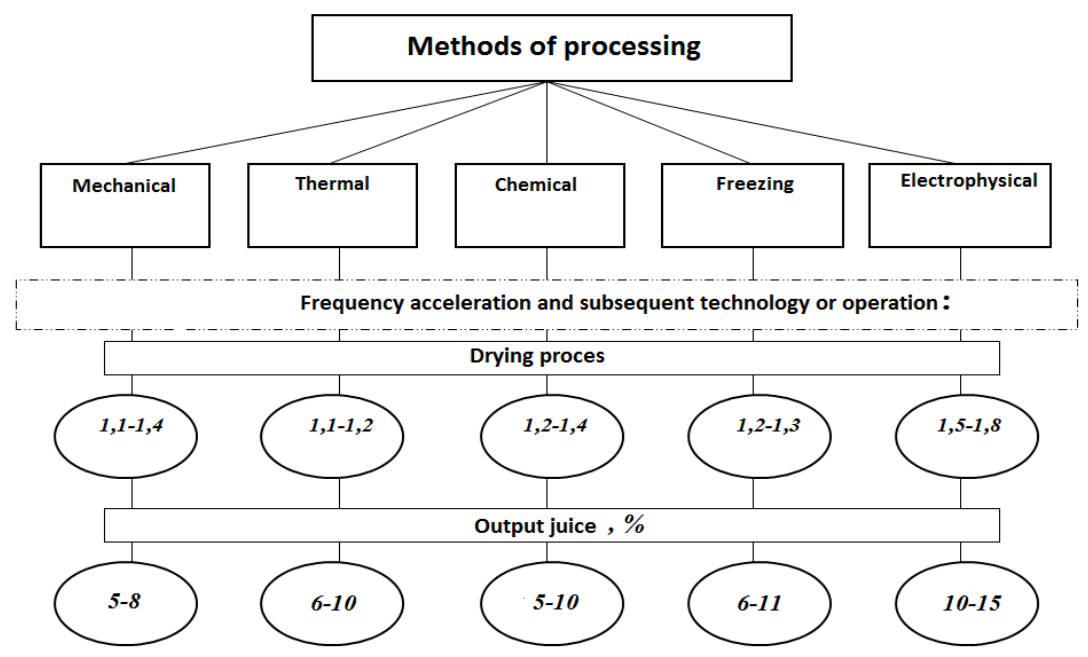

Figure 8: Comparative indicators of the Effectiveness of Methods for Processing Fruits and Vegetables Before Drying and Squeezing Juice

This storage technology has yielded positive results in large vegetable-fruit stores

At present, the construction of not very expensive small storage facilities for agricultural products in the farms themselves is developing widely. Most of them are not equipped with refrigeration units and have only natural or active ventilation, as a result of which they often do not provide the required storage conditions and lead to a decrease in the efficiency of production of the final product. For the last 10 years, we have conducted a study on the effect of zonation on the safety of fruits and vegetables stored in these simplest storages $(21,22,23)$. A distinctive feature was the fact that the impulse technology of ozone treatment was used taking into account the storage period (Figure 9). Thus, for example, grapes of "Nimrang" and "Typhi" varieties were treated during treatment periods with an ozone concentration of 30-35 mg / m3 with a frequency of every 4th day for 4-5 hours. In the main period of storage, the treatment parameters were as follows: ozone concentration 18-20 mg / m3 at a frequency of once a week for 3-4 hours. At the same time, the preservation of grapes averaged $86 \%$. 


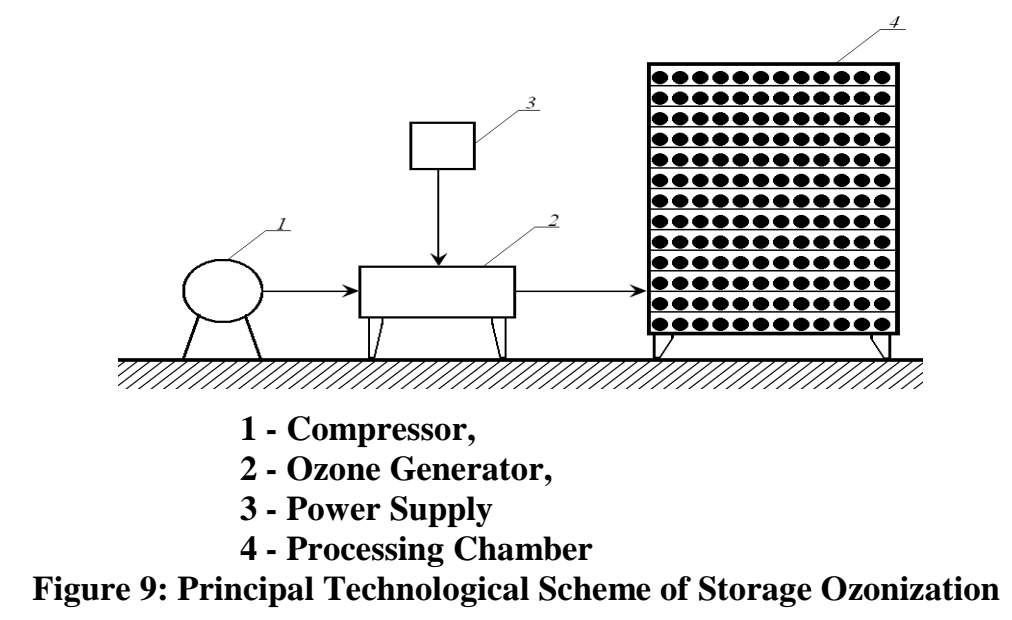

In order to increase the energy efficiency of the process of electro-ozonization, the issue of the combined use of both traditional and Renewable Energy Sources (RES) was considered. The principles and requirements for connection of renewable energy sources for power supply of electro-ozonizers are grounded.

It is of great interest to widely use renewable energy sources both in heat treatment processes and in low-power electrical processing and storage processes.

The calculations and data of other researchers carried out by us showed that the energy potential of renewable energy sources of the republic is sufficient to cover more than $40 \%$ of the needs of technological processes of processing and storage of the country's produce.

\section{CONCLUSIONS}

- In the existing technology for the production of dried products and the production of juices from fruits, vegetables, and grapes, the most energy-intensive is thermal processes and more than $92 \%$ of the energy consumed by the total energy consumed for all processes is consumed. In drying processes and juice squeezing, the main obstacle to the interruption of moisture and juice from fruit, vegetables, and grapes is the resistance of their cells to those of plant origin. From the pre-treatment methods (mechanical chemical thermal freezing, electro physical etc.) before drying and juice squeezing, in order to reduce energy consumption of drying processes and juice squeezing and also to increase juice yield, the most effective is the electro physical effects, in particular, the electro pulse treatment providing the maximum deadening of tissue cells as the main factor preventing the removal of moisture and juice.

- The developed electro-impulse technology processing fruits and vegetables and grapes before drying $1,5-1,8$ times accelerates the process, reduces the loss of nutrients by 5-7\%, the yield of juice increases by $10-15 \%$. The positive effect of electro-impulse treatment of fruits and grapes was revealed before drying and before squeezing the juice for the duration of storage of dried products and juice.

- In the simplest vegetable and fruit storage facilities functioning today in farming and peasantry farms, we recommend the use of electro-technical processing methods (ozonation, ionization of air, ultraviolet irradiation, UHF and others) which, with insignificant capital expenditures, ensures the safety of production up to $86 \%$. Great prospects have a vacuum method of storage, the widespread use of which is restrained by the lack of inexpensive and efficient installations. The use of renewable energy sources (RES) will significantly reduce the cost of non- 
renewable energy resources (oil products, gas, and others) to processing processes while improving the ecological situation in the region.

- The energy potential of renewable energy sources in the Republic is sufficient to cover more than $40 \%$ of the needs of technological processes for processing and storing fruit and vegetables.

\section{Thanks}

- Fundamental project KX-4Ф-22 on the theme "Scientific and methodological principles of saving thermal and electric energy in agricultural production" (2012-2014) Tashkent state agrarian university "TSAU"

- Applicable project KXA-9-100, Development of energy-resource shunting, environmentally safe electro technologies and technical means of storage and processing of agricultural products based on the integrated use of traditional and renewable energy sources. "(2012-2014)"“"TSAU"

- Innovative project ҚХИ-3-001-2013 on "Development and application of a unified modular biogas plant" (2013-2014) "TSAU"

- Application project KXA-4-004-2015 - "Development of a local energy supply system for consumers of farms specializing in fruit growing and viticulture based on the integrated use of renewable energy sources," 2015-2017 y. "TSAU"

- Is the executor of the Interagency Innovative Project jointly carried out by the Scientific Research Institute of Power Automation of the Academy of Sciences of the Republic of Uzbekistan and "TSAU" (И-2015-3-4) "Development and development of production of energy-efficient equipment and renewable energy sources with the creation of a demonstration-testing ground", 2015-2016

- Is the executor of the innovative project (И-204-15-2-21) performed in the Research Institute: Power engineering and automation of the Academy of Sciences of the Republic of Uzbekistan - "Development, creation and implementation of mini HPPs ( hydroelectric power plant) up to $100 \mathrm{~kW}$ with increased power quality indicators and preparation of RES literature", 2015-2016 .

\section{REFERENCES}

1. N. K. Thakur, N. S. Thakur Drying of Fruits and Vegetables. Postharvest Technology of Fruits \& Vegetables, Indus Publishing Co., New Delhi, India (2000) pp. 821-895

2. Beker CGJ (2005) Energy efficiency in drying. Stewart Post-harvest Rev 4:8-12

3. Pento V.B. Technology and technology of drying. // Food industry.2005. № $9 *$ * P. 14-16.

4. Nemenushaya L.A. Modern technologies of storage and processing of fruits and vegetables / Nemenushaya L.A., N.M. Stepanisheva, D.M. Solomatin.M .: FGNU "Rosinformagrotekh", 2009. - 172 p.

5. Tzempelikos DA, Vouros AP, Bardakas AV. Case studies on the effect on the effect of the air drying conditions on the convective drying of quinces. Case Studies in Thermal Engineering.2014;3:79-85

6. Mirzaev, M.M., etc. Technology of cultivation and drying of grapes.-Toshkent.: Uzbekistan, 1982.-41 p.

7. Moses JA, Norton T, Alagusundaram K, et al. Novel drying techniques for the food industry. Food Engineering Reviews. 2014; 6: $43-55$ 
8. Erle U (2005) Drying using microwave processing. In: The microwave processing of foods. Schubert H, Regier M (ed), Woodhead Publ, Cambridge, England, p 142-152

9. Boyko.A.AI Electroplosmolysis of plant objects // Mechanization and electrification of socialist agriculture 1977 № 2 p. 42

10. Romaswanny H., Voort F. R. Van de. Microwave applications in food processing // Can. Eust., Food Sci. Am Technol. Y. 1990. V. 23. № 1. P. 17-21.

11. Schreier, P., Reid, D., and Fryer, P. (1993). Enhanced diffusion during the electrical heating of foods. Int. J. Food Sci. Technol., 28, 249-260.

12. Method of preparing fruits and grapes for drying. A. Rajabov, M. Mirzaev, A. Mukhammadiev, E. V. Stavikin, A. Kh. Vahidov (USSR) No. 3493088 /28-13; Declared September 22, 822; published 15.05.84. bul. No. 18.

13. A. S. SSSR No. 13981123. Method of preparing melons for drying. Radzhabov A., Muratov H., Rasulov A. January 22, 1988

14. A. S. SSSR № 1614785. Devices for preparing plant materials for drying. Radzhabov A., Muratov H., Faizullaev S., Muzaffarov S. August 12, 1990

15. A.S. No. 1758925. Method for drying melon pulp. Radzhabov A., Muratov H., Ahmedov O., May 1, 1992

16. Radzhabov A., Khasanov U. Electro processing of products before drying // Food Industry, 1991. N4.-p.65-67.

17. Radzhabov A. Fundamentals of energy-saving technology of drying food products. "Herald of agricultural science“,1991.N5.p. $68-72$

18. Radzhabov A., Muratov H., Ismoilov M., Scientific basis of energy perfection production of dried fruits and sultana grape. Monograph. Tashkent.: Mehnat, 1993.-p.110

19. Eshpulatov N.M, Salomov M. Electrotechnical methods for increasing energy efficiency in the production of fruit and grape juices. Priority directions of development of modern science of young agricultural scientists. Materials of the Vth International Scientific and Practical Conference of Young Scientists, dedicated to the 25th anniversary of the FGIBNU "The Caspian Institute of Arid Agriculture ". from. “Salonoe Zaimishche” May 11-13, 2016 784-787 p.

20. Saifee, A., \& Mittal, A. R. V. I. N. D. (2014). Design of novel axial flux permanent magnet generator (AFPMG) for wind energy applications. Int J Electr Electr Eng Res, 4(3), 35-42.

21. Radzhabov A., Ibragimov M., Eshpulatov N.M. Increase of energy efficiency of processing and storage of fruit and vegetable products in the Republic of Uzbekistan. Materials of the international scientific and practical conference "Problems of increasing the efficiency of the use of electrical energy in the agro-industrial complex". May 25-26, 2015. - pages 49-52

22. Ibragimov M., Babaev A.G. The use of ozone in storages of fruits and vegetables. Collection of scientific works. Kazakh National Agrarian University. Part I - Almaty 2008, p. 204-208

23. Ibragimov M., Babaev A.G. Increase the safety of fruits and vegetables by ozonization. Ecologically clean resource-saving technologies of cultivation, storage and reproduction of agricultural products. Republican Scientific and Practical Conference - Tashkent: “TSAU”, 2009-233-235.page

24. Ibragimov M., Babaev A.G. Improvement of energy characteristics of electric ozone generators. The role of agrarian science and scientific and technical information in innovative development of agriculture. Materials of Republican scientific-practical conference. Part I - Tashkent: “TSAU”, 2010-272-275 p. 
